\title{
ALGAS PLANCTÔNICAS DE UM LAGO ARTIFICIAL DO JARDIM BOTÂNICO CHICO MENDES, GOIÂNIA, GOIÁS: FLORÍSTICA E ALGUMAS CONSIDERAÇÕES ECOLÓGICAS
}

\author{
NOGUEIRA, I. de S., ${ }^{1}$ e LEANDRO-RODRIGUES, N. C. ${ }^{2}$ \\ ${ }^{1}$ Universidade Federal de Goiás, Campus II, Instituto de Ciências Biológicas I, Departamento de Botânica, C.P. 131, \\ CEP 74001-970, Goiânia, Goiás, e-mail: nogueira@icb1.ufg.br \\ ${ }^{2}$ Universidade Católica de Goiás, Departamento de Ciências Biológicas e Biomédicas, \\ C.P. 86, CEP 74605-010, Goiânia, Goiás \\ Correspondência para: Ina de Souza Nogueira, Universidade Federal de Goiás, Campus II, Instituto de Ciências \\ Biológicas I, Departamento de Botânica, C.P. 131, CEP 74001-970, Goiânia, Goiás, e-mail: nogueira@icb1.ufg.br \\ Recebido em 06/02/97 — Aceito em 20/11/98 — Distribuído em 10/09/99
}

(Com 39 figuras)

\begin{abstract}
Planctonic algae of an artificial lake of Chico Mendes Botanical Garden, Municipality of Goiânia, State of Goiás: floristic and some ecological considerations
\end{abstract}

This paper aims to study the composition and some ecological aspects of the phytoplancton of one of the artificial lakes located at "Chico Mendes" Botanical Garden, Goiânia, Goiás, midwest region of Brazil. The floristic and some ecological aspects were analised. The samples were collected during the following periods: dry, begining of the rainy season and rainy. Besides the phytoplancton, some abiot parameter were mensured $(\mathrm{pH}$, oxygen, temperature, nitrate, nitrite, alkalinity, chlorite, turbity, BDO e precipitation), 77 taxa belonging to taxonomic classes were recognized and 37 taxa was recorded for the first time to State of Goiás. Chlorophyceae was the most representative class. During rainy period the greatest richness was registered, with 11 abundant taxa. In contrast, at the begining of the rainy season the highest phytoplanktonic density was observed $(13,590 \mathrm{ind} / \mathrm{ml})$ with 18 abundant taxa, in special Nephrochlamys allantoidea (Chlorophyceae) and Phacus dangeardi (Euglenophyceae). The water was warm $\left(24^{\circ}-26^{\circ}\right)$, lightly acid through alkalin and meso to oligotrophic.

Key words: Phytoplankton, floristic, ecologicals aspects.

\section{RESUMO}

Este trabalho visa estudar a composição e fazer algumas considerações ecológicas das algas planctônicas que ocorrem em um dos lagos artificiais do Jardim Botânico Chico Mendes, Goiânia, Goiás, enfocando a florística e aspectos ecológicos entre períodos de seca, início de chuva e período chuvoso, juntamente com alguns parâmetros abióticos ( $\mathrm{pH}$, oxigênio - dissolvido e saturado - temperatura do ar e da água, nitratos, nitritos, alcalinidade, cloretos, turbidez, DBO e precipitação). Foram reconhecidos 77 táxons, distribuídos em 9 classes, destes $68,7 \%$ foram registrados como sendo primeira ocorrência para o estado e Chlorophyceae, a classe mais representativa. Durante o período chuvoso observou-se maior riqueza específica, com 11 táxons abundantes. No entanto, o início das chuvas apresentou maior densidade fitoplanctônica (13.590 ind/ml), com 18 espécies abundantes, dentre estas se destacaram Nephrochlamys allanthoidea (Chlorophyceae) e Phacus dangeardi (Euglenophyceae) que apresentaram elevadas densidades. As águas do ambiente estudado mostraram-se com características meso a oligotróficas no período seco e oligotróficas no início das chuvas, variando de levemente ácida a alcalina, com temperatura entre $24^{\circ} \mathrm{C}$ e $26^{\circ} \mathrm{C}$.

Palavras-chave: Fitoplâncton, florística, aspectos ecológicos, lago artificial. 


\section{INTRODUÇÃO}

Os ecossistemas artificiais urbanos foram desenvolvidos com a finalidade de proporcionar ao homem melhores condições de vida. Entretanto, nos ecossistemas fechados, alguns grupos de algas podem desenvolver altas densidades populacionais, inibindo, até mesmo, o crescimento de outros organismos (Round, 1983).

Dentre os trabalhos efetuados nos ambientes artificiais urbanos que citam a ocorrência de algas destacam-se os seguintes: Kleerekoper (1937, 1939); Rennó (1958); Joly (1963); Branco (1966); Andrade (1969); Derisio \& Montebello (1972); Flores (1972), Leite (1974); Lyra (1974); Rosa et al. (1974); Rocha \& Narduzzo (1975); Cecy et al. (1976); Hino \& Tundisi (1977); Tundisi (1977); Aguiar \& Martan (1979); Roque (1980); Tavares (1981); Tundisi \& Hino (1981); Xavier (1981a e 1981b); Paula et al. (1982); Dias (1983); Freitas (1983); Peixoto \& Huszar (1983); Bicudo (1984); Giani (1984); Sant'Anna (1984); Dias (1985); Cecy (1986); Giani \& Pinto-Coelho (1986); MatsumuraTundisi \& Tavares (1986); Sophia (1987); Menezes (1987); Picelli-Vicentim (1987); Sant'Anna et al. (1989); Xavier (1989a e 1909b), Menezes (1989, 1990, 1991a e 1991b); Agujaro (1991); Martins et al. (1991); Menezes (1992); Necchi \& Bicudo (1992); Dias (1992); Alves-da-Silva \& Torres (1994); Menezes (1995, 1996); Bicudo (1996) e Nogueira (1996).

Para a região Centro-Oeste ressaltam-se os trabalhos de Branco (1976); Cronberg (1976); Lindmark (1977); Chaves (1978); Almeida (1979); Pinto-Coelho (1983); Pinto-Coelho \& Giani (1985); Ferreira (1988); Branco \& Senna (1991, 1994); Senna (1994, 1996); Branco \& Senna (1996a e 1996b), no Lago Paranoá em Brasília. No Estado de Goiás, os ambientes artificais têm sido incluídos nos trabalhos de flora (Dias \& Sophia, 1994; Menezes et al., 1995). As algas referidas especificamente para o Município de Goiânia estão relacionadas em Macedo-Saidah et al. (1987); Campos \& Macedo-Saidah (1990); Crispim et al. (1992); Rebouças-Bessa \& Reis (1992); Paiva (1994); Chagas (1994); Rebouças-Bessa \& Santos (1995). Esses trabalhos referem-se a ambientes artificiais, enquanto Campos et al. (no prelo) e Saneago (1996) referem-se a estudos em ambiente lótico.

$\mathrm{O}$ presente trabalho visa estudar as algas planctônicas ocorrentes em um dos lagos artifi- ciais do Jardim Botânico Chico Mendes, enfocando a florística e alguns aspectos ecológicos.

\section{MATERIAL E MÉTODOS}

O Jardim Botânico Chico Mendes localizase no Estado de Goiás (Figs. 1 e 2), município de Goiânia $\left(49^{\circ} 17^{\prime} \mathrm{W}, 16^{\circ} 41^{\prime} \mathrm{S}\right)$, e está a $840 \mathrm{~m}$ de altitude. Foi construído por volta de 1978, sendo, atualmente, uma das maiores reservas biológicas do município. A área tem sofrido inúmeras agressões antrópicas ao longo dos anos, que prejudicaram suas características ambientais. Existem basicamente três nascentes, cada uma delas constituída de um ou vários "olhos-d'água" que, juntos e represados, formam os lagos artificiais do Jardim Botânico que desaguam formando o Córrego Botafogo.

Foram efetuadas 6 excursões ao Jardim Botânico entre períodos de seca (31/08/94), início de chuva (31/10/94) e período chuvoso $(31 / 01 / 95,24$ / 02/95 e 03/04/95) para coletas no Lago II. As algas analisadas neste estudo foram provenientes de amostras quantitativas coletadas subsuperficialmente e fixadas com solução de lugol-acético (Vollenweider, 1974).

Foram coletadas também amostras para o estudo qualitativo complementar, obtidas através de filtração da água por rede de plâncton de $25 \mu \mathrm{m}$. Parte da amostra foi mantida viva, sob refrigeração, e parte foi fixada no momento da coleta com solução de Transeau, na proporção de 1:1 (Bicudo \& Bicudo, 1970), e incorporada ao Herbário UFG, conforme registros a seguir: UFG 11311 (N.C.L.-1); UFG 11314 (N.C.L.-2); UFG 11315 (N.C.L.-3); UFG 11316 (N.C.L.-4); UFG 11317 (N.C.L -5); UFG 11322 (N.C.L-6); UFG 11323 (N.C.L-7); UFG 11324 (N.C.L.-8); UFG 11325 (N.C.L.-9).

Os sistemas de classificação adotados neste trabalho foram: para as Chlorococcales, o de Komárek \& Fott (1983); para as Ulothricales, o de Hindak (1987); para as Tribophyceae (= Xanthophyceae), o de Ettl (1978); para Cyanophyceae, o de Anagnostidis \& Komárek (1988); para as Bacillariophyceae, o de Simonsen (1979); para as Chrysophyceae, o de Starmach (1985); e para as Euglenophyceae, o de Hollande (1942).

As amostras foram quantificadas em microscópio invertido, Olympus modelo IMT-2, com 400 aumentos, de acordo com o método de Utermöhl (1958), a partir de campos distribuídos aleatoria- 


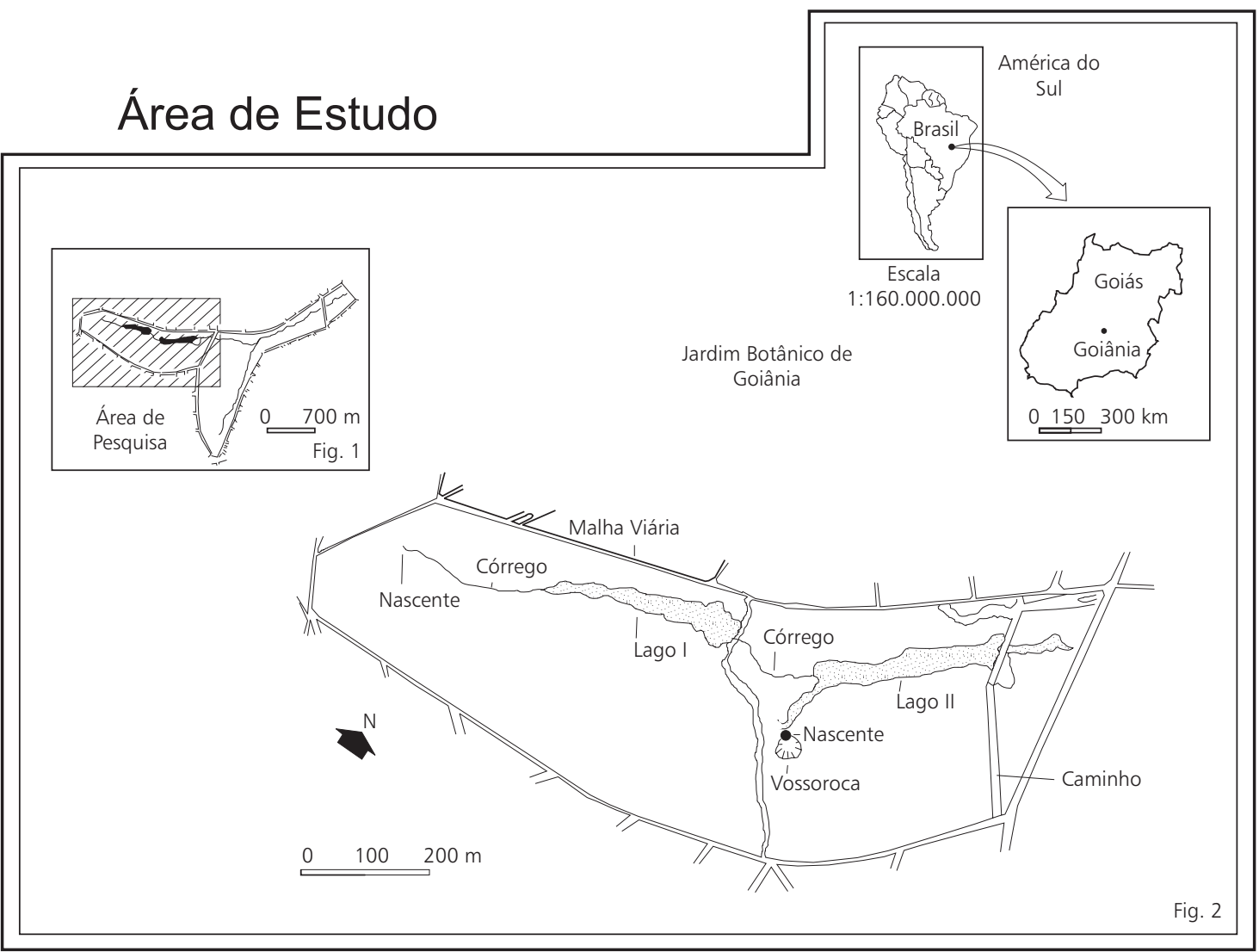

Fig. 1 - Localização do Jardim Botânico de Goiânia. Fig. 2 - Área de pesquisa no Jardim Botânico de Goiânia.

mente (Uhelinger, 1964), sendo sorteadas abscissas e ordenadas a cada novo campo. A quantificação dos organismos foi feita até alcançar, sempre que possível, 100 organismos (cenóbios, colônias, filamentos e células) da espécie mais freqüente ou até estabilizar o número de espécies adicionadas por campo (área mínima de compensação). Desse modo, o erro de contagem foi inferior a $20 \%$, em um nível de significância de 95\% (Lund et al., 1958).

Alguns parâmetros da comunidade fitoplanctônica foram analisados. Foram consideradas espécies abundantes e dominantes de acordo com Lobo \& Leighton (1986).

A riqueza específica (número de táxons) correspondeu ao número total de táxons, presente em cada amostragem. A eqüidade $\left(\mathrm{Js}=100 . \frac{\left(\mathrm{H}^{\prime}\right)}{\operatorname{LnN}}\right) \mathrm{e}$ a diversidade específica $\left(\mathrm{H}^{\prime}=-\Sigma\right.$ pi $\left.\log 2 \mathrm{Pi}\right)$ foram calculadas através do programa DIVERS (Krebs, 1989). Na análise numérica, utilizou-se a similaridade que foi calculada a partir do coeficiente de
Sprensen, posteriormente, WPGMA (Weight pairgroup method using arithmetic averages) e análise de grupamento (Sneath \& Sokal, 1973). Todas essas operações foram efetuadas através do programa NTSYS, versão 1.7 (Rohlf, 1992).

Foram medidos alguns parâmetros abióticos: $\mathrm{pH}$, oxigênio - dissolvido e saturado - temperatura do ar e da água, nitratos, nitritos, alcalinidade, cloretos, turbidez, DBO e precipitação, de acordo com Standard Methods, (Clesceri et al.,1992).

Os valores de precipitação foram levantados no Posto Metereológico da Universidade Federal de Goiás.

\section{RESULTADOS}

\section{Fitoplâncton}

Na comunidade fitoplanctônica foram identificados 77 táxons, distribuídos em 9 classes, sendo 24 Chlorophyceae, 14 Euglenophyceae, 10 Cyanophyceae, 5 Chrysophyceae, 5 Xantho- 
phyceae, 4 Zygnemaphyceae, 3 Bacillariophyceae, 3 Cryptophyceae e 2 Dinophyceae. A lista dos táxons encontra-se na Tabela 1 e foram descritos apenas os 34 táxons identificados em nível infragenérico que constituem novidades para o Estado de Goiás.

TABELA 1

Densidade (ind/ml), dominância (D), abundância (A) dos táxons registrados no ambiente de estudo durante as amostragens.

\begin{tabular}{|c|}
\hline Lista de táxons \\
\hline I - CYANOPHYCEAE \\
\hline 1 - Borzia aff. periklei Anagn. \\
\hline 2 - Gloeothece coerulea Geitler \\
\hline 3 - Gloeothece linearis Näg \\
\hline $4-$ Microcystis sp. \\
\hline 5 - Oscillatoria sp. ${ }^{1}$ \\
\hline $6-$ Oscillatoria sp. ${ }^{2}$ \\
\hline 7 - Planktolyngbya subtilis (W. West) Anag. Kom. \\
\hline 8 - Snowella lacustris (R. Chod.) Kom \& Hind \\
\hline 9 - Synechococcus cedrorum Sauvageau \\
\hline 10 - Synechococcus elongatus Näg \\
\hline 11 - Cyanophyceae sp. ${ }^{1}$ \\
\hline $12-$ Cyanophyceae sp. $^{2}$ \\
\hline 13 - Cyanophyceae sp. ${ }^{3}$ \\
\hline II - CHLOROPHYCEAE \\
\hline $14-$ Chlorella oocystoides Hind \\
\hline 15 - Clamydomonas sp. \\
\hline 16 - Coelastrum reticulatum (Dang.) Senn. \\
\hline 17 - Diacanthos belenophorus Kors. \\
\hline 18 - Dictyosphaerium pulchellum Wood \\
\hline $\begin{array}{l}\text { 19- Pseudodidimocystis fina (Kom) } \\
\text { Hegew \& Deason }\end{array}$ \\
\hline 20 - Elakatothrix minima Beck-Manngetta \\
\hline 21 - Golenkinia radiata $\mathrm{R}$. Chod \\
\hline $22-$ Kirchneriella $\mathrm{sp}$. \\
\hline $\begin{array}{l}23 \text { - Koliella longiseta (Vischer) } \\
\text { Hind } f \text {. tenuis } \mathrm{Nyg}\end{array}$ \\
\hline 24 - Monoraphidium arcuatum (Kors.) Hind \\
\hline 25 - Monoraphidium minutum (Näg.) Kom.-Leg. \\
\hline 26 - Nephrochlamys allanthoidea Kors \\
\hline 27 - Nephrochytium agardhianum Näg \\
\hline 28 - Pediastrum duplex Meyen \\
\hline 29 - Quadricoccus laevis Fott \\
\hline $\begin{array}{l}30 \text { - Rhaphidiocelis contorta (Schmidle) } \\
\text { Marvan } \text { et. al., var contorta }\end{array}$ \\
\hline 31 - Rhaphidiocelis danubiana (Hind) Marvan et. al. \\
\hline
\end{tabular}

\begin{tabular}{|c|c|c|c|c|c|}
\hline \multicolumn{2}{|c|}{ Seca } & \multirow{2}{*}{$\begin{array}{c}\begin{array}{c}\text { Início de } \\
\text { chuva }\end{array} \\
\text { 31/10/94 }\end{array}$} & \multicolumn{3}{|c|}{ Chuva } \\
\hline $31 / 08 / 94$ & $04 / 10 / 94$ & & $31 / 01 / 95$ & 24/02/95 & |03/04/95 \\
\hline 2 & - & - & - & - & - \\
\hline 1 & - & - & - & $12^{\wedge}$ & - \\
\hline- & - & - & - & - & 32 \\
\hline- & - & $548^{\AA}$ & - & - & 32 \\
\hline 2 & - & $548^{\mathrm{A}}$ & - & - & - \\
\hline 1 & - & - & - & 6 & - \\
\hline 2 & - & - & $64^{A}$ & - & 32 \\
\hline- & - & - & 32 & - & - \\
\hline- & 4 & - & - & - & - \\
\hline- & - & - & 32 & - & 32 \\
\hline 3 & - & $548^{A}$ & - & - & - \\
\hline- & - & - & - & 6 & 32 \\
\hline- & - & 164 & - & - & - \\
\hline 1 & 4 & - & - & - & - \\
\hline- & - & - & 32 & - & - \\
\hline 2 & - & - & - & $13^{\mathrm{A}}$ & - \\
\hline- & - & $548^{A}$ & - & - & - \\
\hline- & - & 219 & - & 19 & 32 \\
\hline 4 & - & - & - & - & - \\
\hline $9^{\wedge}$ & 8 & - & - & - & - \\
\hline- & - & $931^{A}$ & - & 6 & - \\
\hline 3 & 8 & - & - & - & - \\
\hline $97^{\mathrm{A}}$ & $475^{\mathrm{D}}$ & - & - & $13^{A}$ & 32 \\
\hline- & 8 & 110 & - & - & - \\
\hline 12 & 17 & 110 & - & 6 & - \\
\hline- & - & $1096^{\mathrm{A}}$ & - & - & - \\
\hline- & 4 & - & - & - & - \\
\hline 4 & - & - & - & - & 32 \\
\hline- & - & - & - & 6 & - \\
\hline- & - & - & - & $12^{\mathrm{A}}$ & - \\
\hline 2 & - & - & - & $12^{A}$ & - \\
\hline
\end{tabular}


TABELA 1

Densidade (ind/ml), dominância (D), abundância (A) dos táxons registrados no ambiente de estudo durante as amostragens (continuação).

\begin{tabular}{|c|c|c|c|c|c|c|}
\hline \multirow{2}{*}{ Lista de táxons } & \multicolumn{2}{|c|}{ Seca } & \multirow{2}{*}{$\begin{array}{c}\text { Início de } \\
\text { chuva } \\
31 / 10 / 94\end{array}$} & \multicolumn{3}{|c|}{ Chuva } \\
\hline & 31/08/94 & 04/10/94 & & 31/01/95 & 24/02/95 & 03/04/95 \\
\hline 32 - Scenedesmus ellipticus Corda & 2 & 30 & - & - & 6 & - \\
\hline $\begin{array}{l}33 \text { - Scenedesmus opoliensis P. Richter var } \\
\text { mononensis R.Chod }\end{array}$ & - & - & $658^{\mathrm{A}}$ & - & - & 32 \\
\hline 34 - Scenedesmus ovalternus R. Chod & - & 30 & 110 & - & - & - \\
\hline 35 - Scenedesmus sp. & - & - & 110 & - & - & - \\
\hline 36 - Selenastrum rinoi Kom. \& Comas & - & - & $548^{\mathrm{A}}$ & - & - & - \\
\hline 37 - Westella botryoides (W.West) De Wild & - & 4 & - & - & - & - \\
\hline 38 - Chlorophyceae sp. ${ }^{1}$ & - & - & 164 & - & - & - \\
\hline $39-$ Chlorophyceae sp. $^{2}$ & - & - & - & 32 & - & - \\
\hline \multicolumn{7}{|l|}{ III - ZYGNEMAPHYCEAE } \\
\hline 40 - Actinotaenium perminutum (G.S.West) Teil & $38^{\mathrm{A}}$ & - & - & - & 6 & - \\
\hline $41-$ Cosmarium sp. & & $98^{\mathrm{A}}$ & & & & \\
\hline $\begin{array}{c}42-\text { Staurastrum inversenii Nyg. var } \\
\text { americanum Scott \& Gronblad }\end{array}$ & - & 13 & - & - & - & - \\
\hline \multicolumn{7}{|l|}{ IV - EUGLENOPHYCEAE } \\
\hline 43 - Teilingia sp. & - & - & - & - & - & 32 \\
\hline 44 - Euglena acus Ehr. var acus & - & - & 164 & - & $13^{\mathrm{A}}$ & - \\
\hline 45 - Euglena limnophila Lemm. & - & - & - & - & 6 & - \\
\hline $46-$ Euglena sp. $^{1}$ & 2 & - & - & - & - & - \\
\hline $47-{\text { Euglena } \text { sp. }^{2}}^{2}$ & - & - & - & - & 6 & - \\
\hline 48 - Lepocinclis ovata (Playf.) Conr. & 1 & - & $548^{\mathrm{A}}$ & 32 & - & - \\
\hline 49 - Lepocinclis pseudo-ovum Conr. & 1 & - & - & - & - & - \\
\hline $50-$ Lepocinclis sp. & - & - & - & - & 6 & - \\
\hline 51 - Phacus agilis Skuja & 2 & - & - & - & $13^{\mathrm{A}}$ & - \\
\hline 52 - Phacus dangeardi Lemm. & - & - & $1096^{\mathrm{A}}$ & - & - & - \\
\hline 53 - Phacus raciborskii Drezepolski & - & - & 110 & - & 6 & - \\
\hline 54 - Phacus sp. & - & - & - & - & $12^{\mathrm{A}}$ & - \\
\hline 55 - Strombomonas ensifera (Daday) Defl. & - & - & - & - & 6 & - \\
\hline 56 - Strombomonas sp. & - & - & - & - & 6 & - \\
\hline 57 - Trachelomonas $\mathrm{sp}$. & 1 & - & - & 32 & - & - \\
\hline \multicolumn{7}{|l|}{ V - CHRYSOPHYCEAE } \\
\hline 58 - Chrysococcus sp. & - & - & - & 32 & - & - \\
\hline 59-Dinobrvon divergens Imhof & - & - & $548^{A}$ & - & $\ldots$ & - \\
\hline 60 - Dinobryon sertularia Ehrenberg & - & - & $548^{\mathrm{A}}$ & - & - & - \\
\hline $61-$ Kephyrion sp. & - & 4 & - & - & - & - \\
\hline 62 - Synura sp. & - & - & - & - & 6 & - \\
\hline \multicolumn{7}{|l|}{ VI - BACCILARIOPHYCEAE } \\
\hline 63 - Aulacoseira agassizii (Ostenfeld) Simonsen & 1 & _ & - & _ & _ & _ \\
\hline $\begin{array}{l}64-\text { Surlntollo mononhnirna (Cleve e } \\
\text { Grunow) Van Heurck }\end{array}$ & $9^{A}$ & $93^{\mathrm{A}}$ & - & $64^{\mathrm{A}}$ & $30^{\mathrm{A}}$ & $128^{\mathrm{A}}$ \\
\hline 65 - Synedra sp. & - & - & $767^{\mathrm{A}}$ & 32 & - & - \\
\hline 66 - Baccilariophyceae sp. & - & - & $548^{A}$ & - & - & - \\
\hline 67 - Naviculaceae sn. & - & 4 & - & 32 & - & - \\
\hline
\end{tabular}


TABELA 1

Densidade (ind/ml), dominância (D), abundância (A) dos táxons registrados no ambiente de estudo durante as amostragens (continuação).

\begin{tabular}{|c|}
\hline Lista de táxons \\
\hline VII - XANTHOPHYCEAE \\
\hline 68 - Centritractus ellipsoideus Starmach \\
\hline $69-$ Goniochloris mutica (A. Br.) Fott \\
\hline 70 - Goniochloris sp. \\
\hline 71 - Tetraedriella jovetii (Bourr.) Bourr. \\
\hline 72 - Tetraplecktron torsum (Skuja) Dedus. - Sceg \\
\hline VIII - DINOPHYCEAE \\
\hline $73-$ Peridinium sp. ${ }^{1}$ \\
\hline $74-{\text { Peridinium } \text { sp. }^{2}}^{2}$ \\
\hline IX - CRYPTOPHYCEAE \\
\hline 75 - Cryptomonas erosa Ehr. \\
\hline 76 - Cryptomonas marsonii Skuja \\
\hline 77 - Cryptomonas obovata Skuja \\
\hline X - TÁXONS NÃO IDENTIFICADOS \\
\hline 78 - Táxon não identificado sp. ${ }^{1}$ \\
\hline 79 - Táxon não identificado sp. ${ }^{2}$ \\
\hline 80 - Táxon não identificado sp. ${ }^{3}$ \\
\hline 81 - Táxon não-identificado sp. ${ }^{4}$ \\
\hline 82 - Táxon não-identificado sp. ${ }^{5}$ \\
\hline 83 - Táxon não-identificado sp. ${ }^{6}$ \\
\hline 84 - Táxon não-identificado sp. ${ }^{?}$ \\
\hline 85 - Táxon não-identificado sp. ${ }^{8}$ \\
\hline 86 - Táxon não-identificado sp. ${ }^{9}$ \\
\hline 87 - Táxon não-identificado sp. ${ }^{10}$ \\
\hline
\end{tabular}

\begin{tabular}{|c|c|c|c|c|c|}
\hline \multicolumn{2}{|c|}{ Seca } & \multirow{2}{*}{$\begin{array}{c}\begin{array}{c}\text { Início de } \\
\text { chuva }\end{array} \\
\text { 31/10/94 }\end{array}$} & \multicolumn{3}{|c|}{ Chuva } \\
\hline $31 / 08 / 94$ & 04/10/94 & & $31 / 01 / 95$ & $24 / 02 / 95$ & $03 / 04 / 95$ \\
\hline - & - & $548^{\mathrm{A}}$ & - & - & 32 \\
\hline 1 & - & 164 & - & - & - \\
\hline - & - & - & - & 6 & - \\
\hline - & 4 & - & - & - & - \\
\hline- & - & 219 & - & - & - \\
\hline - & - & - & - & - & - \\
\hline 1 & - & - & - & - & - \\
\hline 2 & - & 274 & - & - & - \\
\hline - & - & - & 32 & - & - \\
\hline - & - & $548^{\mathrm{A}}$ & - & - & - \\
\hline- & 4 & - & - & - & - \\
\hline 1 & - & - & - & - & - \\
\hline- & - & $548^{\mathrm{A}}$ & - & - & - \\
\hline - & - & $548^{\mathrm{A}}$ & - & - & - \\
\hline- & - & - & $64^{A}$ & - & - \\
\hline- & - & - & 32 & - & - \\
\hline- & - & - & - & 6 & - \\
\hline- & - & - & - & 6 & - \\
\hline- & - & - & - & 6 & - \\
\hline- & - & - & - & 6 & - \\
\hline- & - & - & - & 13 & - \\
\hline
\end{tabular}

Táxons Infragenéricos Identificados Nostocophyceae (= Cyanophyceae)

Ordem Chroococcales

Família Microcystaceae

Gênero Gloeothece Nägeli

G. coerulea Geitler

Arch. Protistenk., 60: 440, Fig.1, 1927.

Células isoladas, oblongas, 4-6 x 1-1,2 $\mu \mathrm{m}$, $\mathrm{RC} / \mathrm{L}=4-5$, envolvidas por bainha de mucilagem conspícua, um grânulo em cada pólo.

Material examinado: amostra de fitoplâncton total de 31/08/94. Distribuição geográfica no Estado de Goiás: primeiro registro de ocorrência do gênero.

G. linearis Näg.

Gatt. einzell. Alg., p. 58, 1849.
Células isoladas, elípticas, $10 \times 2,5 \mu \mathrm{m}, \mathrm{RC} /$ $\mathrm{L}=$ ca.4, envolvidas por bainha de mucilagem conspícua, ausência de grânulos nos pólos.

Material examinado: amostra de fitoplâncton total de 03/04/95. Distribuição geográfica no Estado de Goiás: primeiro registro de ocorrência.

Gênero Snowella Elenkin

S. lacustris (R. Chod.) Kom. \& Hind. (Fig.4) Algol. Stud. Figs. 50/53, 1988.

Colônias pequenas esféricas, com 4-32 células, 2 a 2 unidas entre si por pedúnculo mucilaginoso. Células elípticas.

Material examinado: amostra de fitoplâncton total de 31/01/95. Distribuição geográfica no Estado de Goiás: primeiro registro de ocorrência do gênero e espécie. 
Gênero Synechococcus Nägeli.

S. cedrorum Sauvageau

Bull. Soc. Bot. France, 39, p. CXV, Taf. VI, Fig. 1, 1892.

Células isoladas, oblongas a elípticas, 4-6 x $2 \mu \mathrm{m}$, pólos arredondados, $\mathrm{RC} / \mathrm{L}=2-3$.

Material examinado: amostra de fitoplâncton total de 04/10/94. Distribuição geográfica no Estado de Goiás: primeiro registro de ocorrência do gênero.

S. elongatus Näg.

Gatt. einzell. Alg., p. 56, 1849.

Células isoladas ou 2 a 2, elípticas, ca. $6 \mathrm{x}$ $2 \mu \mathrm{m}, \mathrm{RC} / \mathrm{L}=\mathrm{ca} .3$.

Material examinado: amostra de fitoplâncton total de 31/01/95 e 03/04/95. Distribuição geográfica no Estado de Goiás: primeiro registro de ocorrência.

Ordem Oscillatoriales

Família Oscillatoriaceae

Gênero Borzia Cohn ex Gommont.

B. aff. periklei Anagn.

Algol. Stud. 50-53: 370, 1988.

Tricomas unisseriados, solitários, com 3 células arredondadas, septo constricto.

Material examinado: amostra de fitoplâncton total de 31/08/94. Distribuição geográfica no Estado de Goiás: primeiro registro de ocorrência.

Família Pseudanabaenaceae Komárek

Gênero Planktolyngbya Anagnostidis \&

P. subtilis (W. West) Anagn. \& Kom. (Fig. 3), Algol. Stud. 50-53: 394, 1988.

Tricomas solitários, retos, providos de bainha mucilaginosa tênue e ultrapassando as extremidades. Células retangulares, tamanhos regulares, 1,2-1,5 x 2,5-2,8 $\mu \mathrm{m}, \mathrm{RC} / \mathrm{L}=$ ca. 0,5 , septos retos; célula apical arredondada, sem caliptra; protoplasma não-granuloso.

Material examinado: UFG 11314. Distribuição geográfica no Estado de Goiás: primeiro registro de ocorrência.

\section{Chlorophyceae}

Ordem Chlorococcales

Família Golenkiniaceae

Gênero Golenkinia R. Chodat

G. radiata R. Chod. (Fig. 5), J. Bot. 8: 305, pl. 3, Figs. 1-24, 1894.

Células esféricas, 5,5-7,7 $\mu \mathrm{m}$ de diâmetro, com numerosos espinhos dispostos regularmente, 8,8 -
$17,7 \mu \mathrm{m}$, retos finos e longos, 1,6-3,2 vezes o diâmetro celular; cloroplasto único, poculiforme, 1 pirenóide reniforme.

Material examinado: UFG 11314. Distribuição geográfica no Estado de Goiás: primeiro registro de ocorrência.

Família Botryococcaceae

Gênero Quadricoccus Fott

Q. laevis Fott, Study.

Bot. Cechoslovaca, 9(1): 11, Fig. 1g, 1948.

Colônias arredondadas, 15-20 $\mu \mathrm{m}$ de diâmetro, 4 células dispostas irregularmente cruciadas ao redor de restos da parede da célula-mãe em forma de calota, mucilagem hialina e inconspícua presente. Células oblongas a oblongo-alargadas, 5-7 x 3,2-4,1 $\mu \mathrm{m}$, pólos arredondados, um deles fixo no resto da parede da célula-mãe; cloroplasto único, alveiforme, 1 pirenóide.

Material examinado: amostra de fitoplâncton total de 24/02/95. Distribuição geográfica no Estado de Goiás: primeiro registro de ocorrência do gênero.

\section{Família Oocystaceae}

Gênero Nephrochlamys Korsikov

N. allanthoidea Kors. (Fig. 8)

Protococcinae, pp. 311-312, Fig. 280, 1953.

Colônias alongadas ou arredondadas, 8 células irregularmente dispostas, mucilagem hialina e conspícua. Células lunadas, 2,2-3,3 $\mu \mathrm{m}$ de diâmetro, 3,8-5,5 $\mu \mathrm{m}$ de altura, ápices arredondados, distância entre os ápices $2,2-5,5 \mu \mathrm{m}$, cloroplasto único, parietal sem pirenóide.

Material examinado: UFG 11317. Distribuição geográfica no Estado de Goiás: primeiro registro de ocorrência do gênero.

Gênero Diacanthos Korsikov

D. belenophorus Kors.

Protococcinae, p. 263, Fig. 217, 1953.

Células isoladas, elípticas, um espinho reto de base alargada, mais longo que a célula em cada pólo; cloroplasto único, parietal, 1 pirenóide.

Material examinado: amostra de fitoplâncton total de 31/10/94. Distribuição geográfica no Estado de Goiás: primeiro registro de ocorrência.

Gênero Nephrocytium Nägeli

$N$. agardhianum Näg. p, 1849.

Gatt. einzell. Algen, p. 79, pl. 3, Fig. C a-

Colônias alongadas a arredondadas, 4 células dispostas linearmente em mucilagem hialina, inconspícua. Células cilíndrico-curvas, pólos 
arredondados; cloroplasto único, parietal, 1 pirenóide.

Material examinado: amostra de fitoplâncton total de 04/10/94. Distribuição geográfica no Estado de Goiás: primeiro registro de ocorrência.

Família Chlorellaceae

Gênero Chlorella Beijerink.

C. oocystoides Hind.

Biol. Práce 36(6): 65, pl. 24, Fig. 3, 1977.

Células oblongo-alargadas a levemente elípticas, $8 \times 3-4 \mu \mathrm{m}$, ápices arredondados ou levemente agudos; cloroplasto único, alveiforme ou em placa, 1 pirenóide.

Material examinado: amostra de fitoplâncton total de 31/08/94 e 04/10/94. Distribuição geográfica no Estado de Goiás: primeiro registro de ocorrência.

Gênero Monoraphidium KomarkováLegnerova.

M. arcuatum (Kors.) Hind. 1970

Algol .Stud. 1: 25, Fig. 9-10, 1970.

Células isoladas, lunadas, $5 \mu \mathrm{m}$ de diâmetro, ápices gradualmente afilados; $25 \mu \mathrm{m}$ de distância entre os ápices; cloroplasto único, parietal, sem pirenóide, incisão nuclear nítida.

Material examinado: amostra de fitoplâncton total de 31/10/94. Distribuição geográfica no Estado de Goiás: primeiro registro de ocorrência.

Gênero Raphidiocelis Hindák

$R$. contorta (Schmidle) Marvan. et al. var. contorta (Fig. 9) 1984.

Arch. Hydrobiol. (supplement): 67(4): 386,

Colônias arredondadas e alongadas, 30-34 $\mu \mathrm{m}$ de comprimento, $4-8$ células dispostas irregularmente em mucilagem hialina e incospícua. Células cilíndricas, 1,1-2,7 $\mu \mathrm{m}$ de diâmetro, levemente curvas, ápices arredondados, em planos diferentes, 4,4-7,7 $\mu \mathrm{m}$ de distância entre os ápices; cloroplasto único, parietal, sem pirenóide.

Material examinado: UFG 11314. Distribuição geográfica no Estado de Goiás: primeiro registro de ocorrência.

R. danubiana (Hind) Marvan et al. (Fig. 10). Arch. Hydrobiol. (supplement): 67(4): 386, 1984.

Colônias arredondadas, $15,5-40 \mu \mathrm{m}$ de diâmetro, com 2-(4-8) células dispostas 2 a 2 no mesmo plano formando um anel em vista frontal, ápices das células tangenciais ou levemente pró- ximos, mucilagem hialina e inconspícua. Células lunadas, 1,7-3,3 $\mu \mathrm{m}$ de diâmetro, 3,3-7,8 $\mu \mathrm{m}$ de altura, incisão mediana em "U", ápices arredondados no mesmo plano, 1,1-3,3 $\mu \mathrm{m}$ de distância entre os ápices; cloroplasto único, parietal sem pirenóide.

Material examinado: UFG 11317. Distribuição geográfica no Estado de Goiás: primeiro registro de ocorrência.

\section{Gênero Selenastrum Reinsch}

S. rinoi Kom. \& Comas

Arch. Hydrobiol. (supplement): 63(3): 276, Fig. 10, 1982.

Colônias de 4 células com lado convexo orientado para o centro da colônia. Células lunadas, ápices gradualmente afilados, dispostos em mesmo plano; cloroplasto único, parietal, sem pirenóide, incisão nuclear conspícua.

Material examinado: amostra de fitoplâncton total de 31/10/94. Distribuição geográfica no Estado de Goiás: primeiro registro de ocorrência.

Família Scenedesmaceae

Gênero Scenedesmus Meyen

S. ovalternus R. Chod.

Z. Hydrol. 3: 164, Fig. 51, 1926.

Cenóbios levemente curvos, 2-4 células dispostas alternadamente. Células elípticas a elípticoalargadas, 14,4-16,6 x 12-19 $\mu \mathrm{m}$, ápices arredondados; cloroplasto único, parietal, 1 pirenóide.

Material examinado: amostra de fitoplâncton total de 04/10/94. Distribuição geográfica no Estado de Goiás: primeiro registro de ocorrência.

Ordem Ulothricales

Família Ulothricaceae

Gênero Elakatothrix Wille

E. minima Beck-Manngetta

Arch. Protistenk, 66: 6, Fig. 6, 1929.

Células envolvidas por bainha de mucilagem inconspícua, as adultas isoladas, fusiformes, ápices gradualmente afilados, ca. 4 x 1,5 $\mu \mathrm{m}$; as jovens dispostas aos pares, em mesmo plano, 1,8-2 x 0,5$1 \mu \mathrm{m}$; cloroplasto único, sem pirenóide. Reprodução por divisão vegetativa em plasto transversal.

Material examinado: amostra de fitoplâncton total de 31/08/94. Distribuição geográfica no Estado de Goiás: primeiro registro de ocorrência.

Gênero Koliella Hindák.

K. longiseta (Visher) Hind f. tenuis Nyg., K. danske. Vidensk. Selsk.

Biol. Skr. 21(1): 72, Fig. 65, 1977. 
Células isoladas, fusiformes, $80-92 \times 1-1,5 \mu \mathrm{m}$, $\mathrm{RC} / \mathrm{L}=61-92$, ápices gradualmente afilados em pêlo, às vezes levemente curvos; cloroplasto único, sem pirenóide. oblíquo.

Reprodução por divisão vegetativa em plano

Material examinado: amostra de fitoplâncton total de 31/08/94. Distribuição geográfica no Estado de Goiás: primeiro registro de ocorrência.

\section{Zygnemaphyceae}

Ordem Zygnematales

Família Desmidiaceae

Gênero Actinotaenium (Nägeli) Teiling

A. perminutum (G. S. West) Teil (Fig.14)

Folia geobot. phytotax, 13: 56, 1978.

Células isoladas, ca. 1,6 vez mais longas que largas, $10-13,8 \times 7,7-8,2 \mu \mathrm{m}$, constricção mediana levemente marcada, seno raso, semicélula hemisférica, vista apical circular; istmo 6,6-7,1 $\mu \mathrm{m}$; cloroplasto em vista apical estrelado com 1 pirenóide central.

Material examinado: UFG 11311, UFG 11324. Distribuição geográfica no Estado de Goiás: primeiro registro de ocorrência.

Gênero Staurastrum Meyen

S. inversenii Nyg var americanum Scott \& Gronblad (Fig. 15)

Acta Soc. Sci. Femmicae II, 2(8): 39 B, pl. 19, Figs. 14 e 15, 1957.

Células isoladas, 1,5 vez mais largas que longas, ca. 16,6 x 11,1 $\mu \mathrm{m}$, seno raso, semicélula subtriangular; processo crenulado, 13,3-21,1 $\mu \mathrm{m}$.

Material examinado: UFG 11317. Distribuição geográfica no Estado de Goiás: primeiro registro de ocorrência.

\section{Euglenophyceae}

Ordem Euglenales

Família Euglenaceae

Gênero Lepocinclis Perty

L. pseudo-ovum Conr. (Fig. 20)

Arch. Protistenk. 82(2): 243, Fig. 58, 1938.

Células isoladas, elíptico-alargadas, ca. $21,1 \mathrm{x}$ $11,1 \mu \mathrm{m}, \mathrm{RC} / \mathrm{L}=1,9$, incluindo processo caudal, pólo anterior truncado, abertura do canal apical, pólo posterior atenuado gradativamente em processo caudal curto, estrias dextrógiras, 1 grão de paramido anular; $8,8 \mu \mathrm{m}$ de diâmetro.

Material examinado: UFG 11317. Distribuição geográfica no Estado de Goiás: primeiro registro de ocorrência.
Gênero Strombomonas Deflandre

S. ensifera (Daday) Defl. (Fig. 25)

Arch. Protistenk. 69(3): 601, Figs. 111-113, $115,1930$.

Lóricas rombóides, $32,2 \times 12,2-14,4 \mu \mathrm{m}, \mathrm{RC} /$ $\mathrm{L}=2,2-2,6$, hialinas, vista polar circular, pólo anterior atenuado abruptamente em colo cilíndrido ou reto, bordo liso, espessamento em anel, 3,3 x 14,4 $\mu \mathrm{m}$, pólo posterior atenuado gradativamente em processo caudal reto, septo basal transversal, parede dupla, lisa.

Material examinado: UFG 11323. Distribuição geográfica no Estado de Goiás: primeiro registro de ocorrência.

Família Dinobryaceae

Gênero Dinobryon Ehrenberg

D. divergens Imhof (Fig. 27)

Jber. naturf. ges. Granbündens, 30: 134, 1887.

Colônias dendróides, bastante ramificadas, indivíduos isolados às vezes presentes; lóricas cilíndricas 38-42 x 10-11 $\mu \mathrm{m}, \mathrm{RC} / \mathrm{L}=3,8$, pólo anterior com margens laterais retas e paralelas; pólo posterior abruptamente afilado, às vezes recurvado, inserido no pólo anterior da lórica inferior, porção mediana da lórica com parede crenulada.

Material examinado: UFG 11317. Distribuição geográfica no Estado de Goiás: primeiro registro de ocorrência.

\section{Bacillariophyceae}

Ordem Coscinodiscales

Família Coscinodiscaceae

Gênero Aulacoseira Thwaites

A. agassizii (Ostenfeld) Simonsen

Bacillaria 2: 56, 1979.

Filamentos de 2-4 células. Frústulas esféricas em vista valvar, 3 dentes marginais, tamanhos iguais, parede celular com estrias paralelas, vista pleural retangular, mais larga do que longa.

Material examinado: amostra de fitoplâncton total de 31/08/94. Distribuição geográfica no Estado de Goiás: primeiro registro de ocorrência.

Gênero Cyclotella Kützing

C. meneghniana Kütz. (Fig. 30)

Die Kieselochalegen Baccilaven der Diatomenn, p.50-pl.30 Fig. 68,1844.

Células isoladas, $(7,5)-10-13 \mu \mathrm{m}$ de diâmetro, frústulas esféricas em vista valvar, parede com estrias radiais e periféricas, $10-11 \mathrm{em} 10 \mu \mathrm{m}$, centro da valva liso; superfície valvar ondulada; vista pleural retangular. 

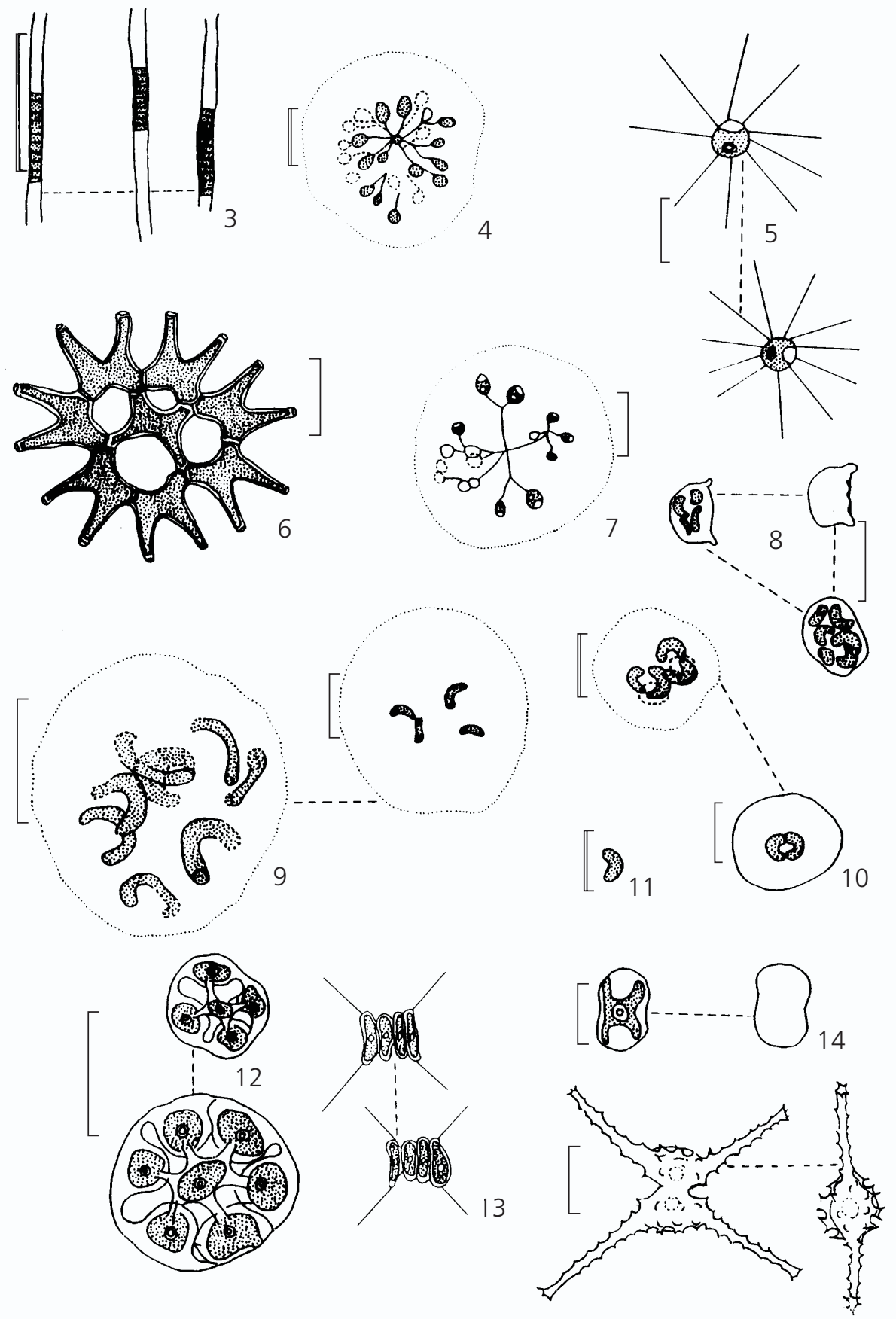

Fig. 3 - Planktolyngbya subtilis (W. West) Anag. \& Kom. Fig. 4 - Snowella lacustris (R. Chod.) Kom. \& Hin.; Fig. 5 Golenkinia radiata R. Chod. Fig. 6 - Pediastrum duplex Meyen. Fig. 7 - Dictyosphaerium pulchellum Wood. Fig. 8 Nephrochlamys allanthoidea Kors. Fig. 9 - Rhaphidiocelis contorta (Schmidle) Marvan et. al. var. contorta. Fig. 10 Rhaphidiocelis danubiana (Hind.) Marvan et. al. Fig. 11 - Monoraphidium minutum (Näg.) Kom.-Leg. Fig. 12 - Coelastrum reticulatum (Dang.) Senn. Fig. 13 - Scenedesmus opoliensis P. Richter var. mononensis R. Chod. Fig. 14 - Actinotaenium perminutum (G.S. West) Teil. Fig. 15 - Staurastrum inversenii Nyg var americanum Scott \& Gronblad.

Escalas: $20 \mu \mathbf{m}$ $10 \mu \mathbf{m}$ 

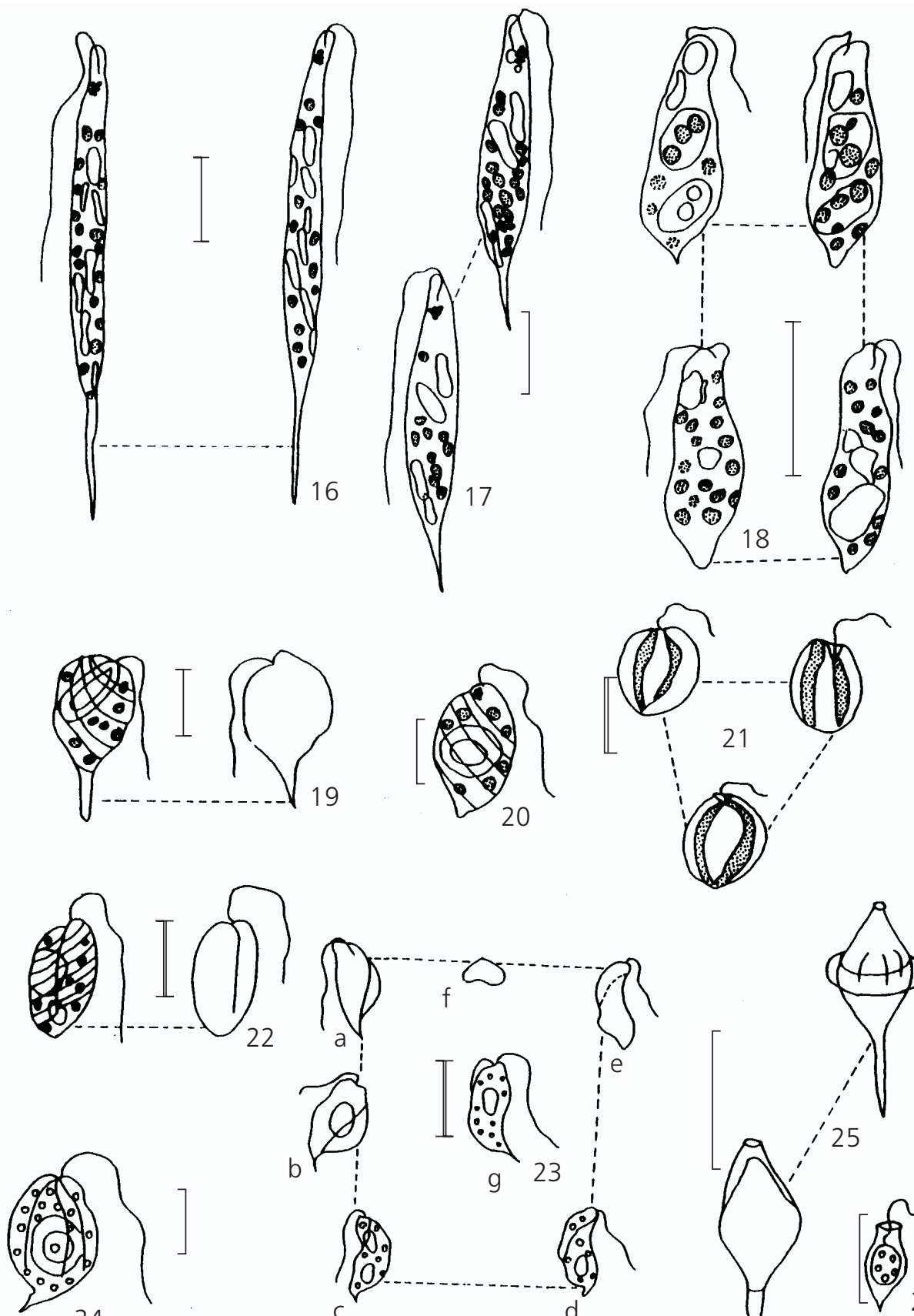

24
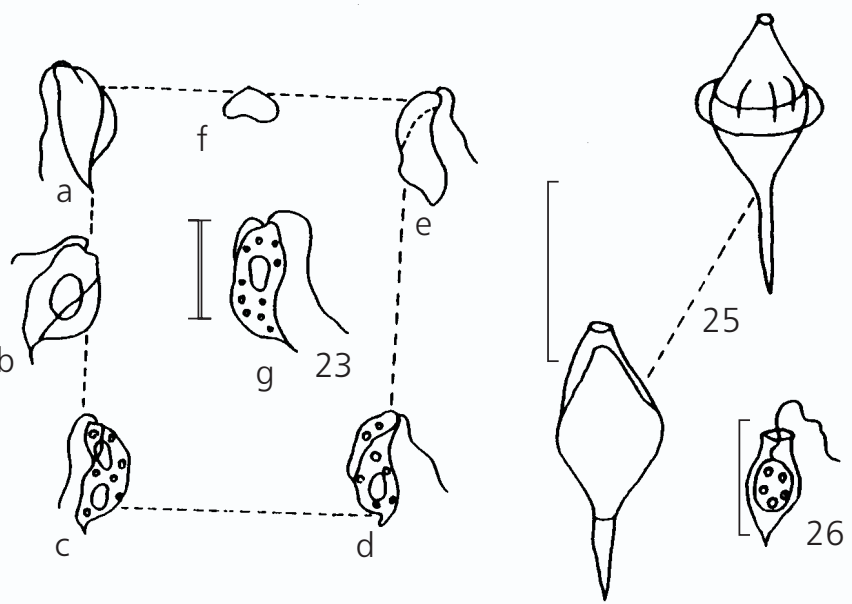

Fig. 16 - Euglena acus Ehr. var acus. Fig. 17 - Euglena limnophila Lemm. Fig. 18 - Euglena sp. Fig. 19 - Lepocinclis ovata Perty. Fig. 20 - Lepocinclis pseudo-ovum Conr. Fig. 21 - Phacus agilis Skuja. Fig. 22 - Phacus dangeardi Lemm. Fig. 23 - Phacus raciborskii Drezepolski. f-vista apical. Fig. 24 - Phacus sp. Fig. 25 - Strombomonas ensifera (Daday) Defl. Fig. 26 - Strombomonas sp. $\mathbf{2 0} \mu \mathbf{m}$ $10 \mu \mathbf{m}$ 
Material examinado: UFG 11316, UFG 11317. Distribuição geográfica no Estado de Goiás: primeiro registro de ocorrência.

\section{Tribophyceae (=Xanthophyceae)}

Ordem Mischococcales

Família Pleurochloridaceae

Gênero Goniochloris Geitler

G. mutica (A. Br.) Fott

Preslia 32: 146, Figs. 2 e 3a, 1960.

Células isoladas, triangulares, lados côncavos, ângulos arredondados, 3 cloroplastos discóides, um em cada ângulo; sem pirenóide.

Material examinado: amostra de fitoplâncton total de 31/08/94 e 31/10/94. Distribuição geográfica no Estado de Goiás: primeiro registro de ocorrência.

Gênero Tetraedriella Pascher

T. jovetii (Bourr.) Bourr (Fig. 32).

Algues d'Eaux Douces, p. 86, v. 2, pl. 36, Fig. 10, 1968.

Células isoladas, tetraédricas, ca.10 $\mu \mathrm{m}$ de largura, lados côncavos, ângulos abruptos, arredondados, parede celular lisa, 3-4 cloroplastos discóides, um em cada ângulo; sem pirenóide, núcleo de coloração laranja, arredondado e central.

Material examinado: UFG 11315. Distribuição geográfica no Estado de Goiás: primeiro registro de ocorrência.

Gênero Tetraplektron Fott

T. torsum (Skuja) Dedus.-Sceg. (Fig. 33)

Opredelitel prisnovodnbch vodoroslej SSR, v. 5, p., 1962.

Células isoladas, em vista frontal tetraédrica ou triangular com processos sobrepostos, 26,6-31,1 $\mu \mathrm{m}$ de lado; vista lateral quandrangular, 10-25,5 $\mu \mathrm{m}$ de largura, ângulos prolongados em processos, margem lateral reta e levemente côncava; numerosos cloroplastos discóides, sem pirenóide.

Material examinado: UFG 11317. Distribuição geográfica no Estado de Goiás: primeiro registro de ocorrência do gênero.

Família Centritractaceae

Gênero Centritractus Lemmermann

C.ellipsoideus Starmach (Fig. 34)

Fragm. Flor. et Geobot. 12, 1966.

Células isoladas elípticas, 13,3-14,4 x 5,5 $\mu \mathrm{m}$, ápices abruptos, prolongando-se em 1 espinho fino e reto, $21,1-27,7 \mu \mathrm{m}$ de comprimento; $3-4$ cloroplastos discóides parietais, sem pirenóide, gotas de óleo presente.
Material examinado: UFG 11311. Distribuição geográfica no Estado de Goiás: primeiro registro de ocorrência.

\section{Cryptophyceae}

Ordem Cryptomonadales

Família Cryptomonadaceae

Gênero Cryptomonas Ehrenberg.

C. erosa Ehr. (Fig. 39)

Phys. Math. Abh. K. Akad, Wiss. Berlin, 1831: 56, 1832.

Células obovadas em vista lateral, elíptica em vista ventral, $12-13,5 \times 5,5-7,7 \mu \mathrm{m}, \mathrm{RC} / \mathrm{L}=1,7$ 1,8 , pólos arredondados, o anterior com 2 flagelos levemente desiguais, subapicais, rostro arredondado; pólo posterior curvo dorsalmente; 2 cloroplastos dorsiventrais, margem levemente lobada; numerosos grãos de amido, arredondados, dispersos no citoplasma; citofaringe oblíqua, inconspícua.

Material examinado: UFG 11323. Distribuição geográfica no Estado de Goiás: primeiro registro de ocorrência.

C. marsonii Skuja (Fig. 37)

Symb. bot. Upsal, 9(3): 357, pl. 37, Figs. 41 e 42, 1948.

Células sigmóides, em vista lateral, obovadas em vista ventral ou dorsal, 8,5-16,1 x 6,6-7,2 $\mu \mathrm{m}$, $\mathrm{RC} / \mathrm{L}=1,3-2,2 ;$ pólo anterior arredondado, com 2 flagelos levemente desiguais, subapicais, rostro arredondado; pólo posterior acuminado terminando em processo caudal cônico, curvo dorsalmente; 2 cloroplastídeos laterais, margem inteira; numerosos grãos de amido alinhados ao longo da margem do plastídeo, citofaringe não-visualizada.

Material examinado: UFG 11323. Distribuição geográfica no Estado de Goiás: primeiro registro de ocorrência.

C. obovata Skuja (Fig. 36)

Symb. bot. Upsal, 9(3): 356, pl. 38, Figs. 46, 1948.

Células obovadas a elípticas em vista lateral, elípticas em vista ventral, ou dorsal, 11-13,5 x 5,5$6,6 \mu \mathrm{m}, \mathrm{RC} / \mathrm{L}=2$; pólos arredondados, o anterior com 2 flagelos levemente desiguais, subapicais, rostro arredondado; 1 cloroplasto em $\mathrm{H}$ ou 2 laterais, margem inteira, numerosos grãos de amido arredondados dispersos no citoplasma; citofaringe oblíqua, 3,8 vezes o comprimento da célula.

Material examinado: UFG 11316. Distribuição geográfica no Estado de Goiás: primeiro registro de ocorrência. 

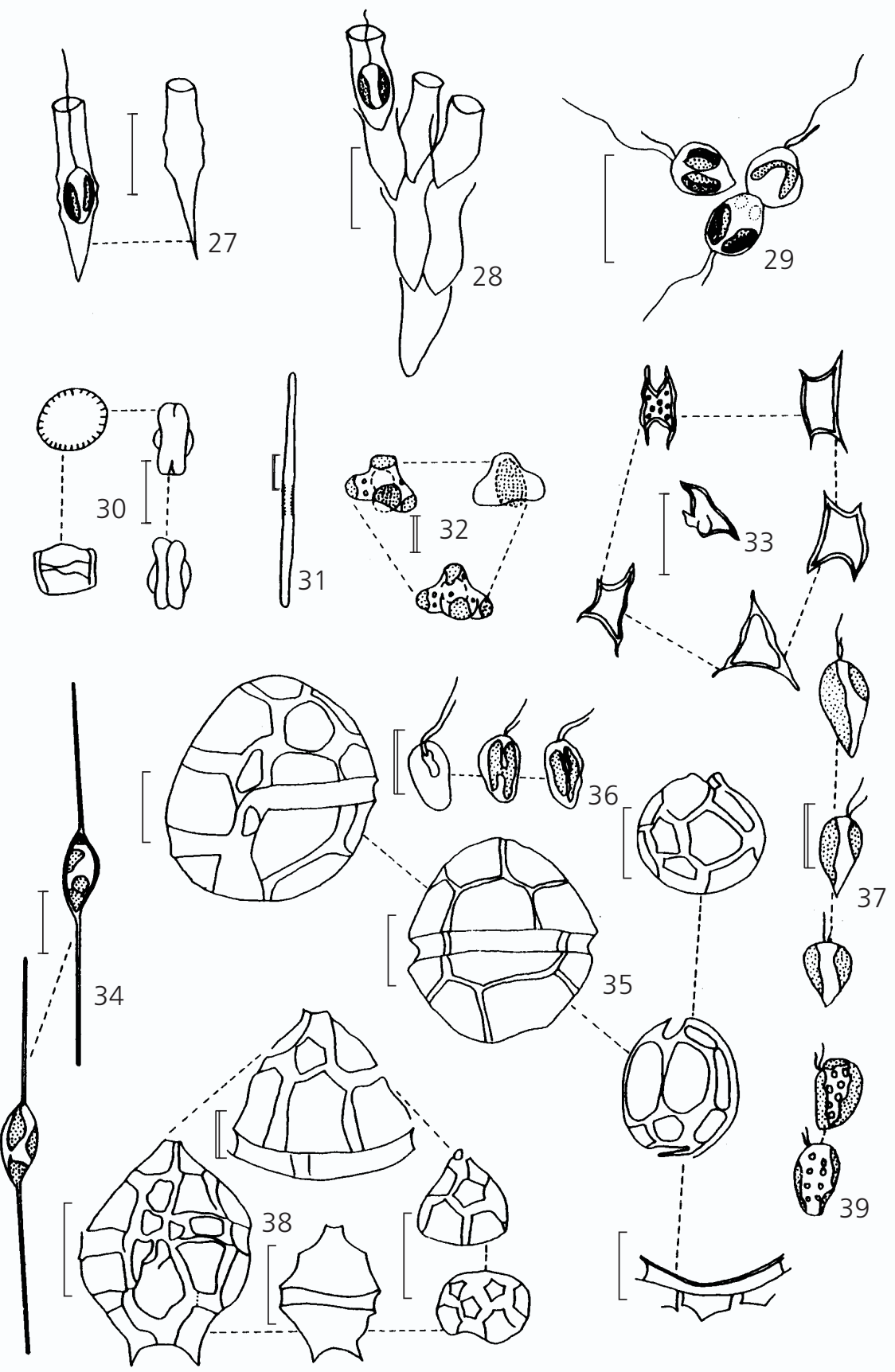

Fig. 27 - Dinobryon divergens Imhof. Fig. 28 - Dinobryon sertularia Ehr. Fig. 29 - Synura sp. Fig. 30 - Cyclotella meneghniana Kütz. Fig. 31 - Synedra sp. Fig. 32 - Tetraedriella jovetii (Bourr.) Bourr. Fig. 33 - Tetraplektron torsum (Skuja) Dedus.-Sceg. Fig. 34 - Centritractus ellipsoideus Starmach. Fig. 35 - Peridinium sp ${ }^{1}$. Fig. 36 - Cryptomonas obovata Skuja. Fig. 37 - Cryptomonas marsonii Skuja. Fig. 38 - Peridinium sp ${ }^{2}$. Fig. 39 - Cryptomonas erosa Ehr. Escalas: $20 \mu \mathrm{m}$ $10 \mu \mathrm{m}$ 


\section{Variáveis abióticas}

A precipitação mínima foi registrada no período de inverno e a máxima no verão (Tabela 2). Os valores da turbidez estiveram abaixo de 25 UNT, que foram indicados por Hammer (1979), para águas límpidas, exceto no período de 03/04/ 95 , pois houve um aumento considerável da turbidez, devido à forte precipitação registrada poucos dias antes da coleta.

As águas do Lago II do Jardim Botânico caracterizaram-se levemente ácidas a alcalinas, e, na seca, de alcalinas a neutras, mantendo-se as- sim até o início das chuvas, decaindo abaixo da neutralidade durante o período chuvoso. (Tabela 2), quando foi observada também uma elevada saturação de oxigênio.

A DBO foi aferida apenas no período seco; comparando-se com as indicações de LangeBertalot (1979), em agosto esta indicou a ausência de características poluidoras na água, enquanto o mesmo não foi observado no período seguinte (Tabela 2). Os níveis de cloretos estiveram elevados, enquanto os de nitrato, moderadamente altos (Tabela 2).

TABELA 2

Flutuação das variáveis físico-químicas em um Lago Artificial do Jardim Botânico entre agosto e outubro de 1994 e entre janeiro e abril de 1995.

\begin{tabular}{|c|c|c|c|c|c|c|}
\hline \multirow[t]{2}{*}{ Variáveis } & \multicolumn{6}{|c|}{ Períodos de coleta } \\
\hline & 31/08/94 & 04/10/94 & 31/10/94 & 31/01/95 & 24/02/95 & $03 / 04 / 95$ \\
\hline PH & 8,4 & 7,2 & 7,2 & 6,5 & 6,0 & 6,7 \\
\hline Oxigênio dissolvido (mg/l) & 8,2 & 6,6 & 5,0 & 5,4 & 6,0 & 5,0 \\
\hline Saturação de oxigênio (\%) & 51 & 78 & 60 & 66 & 74 & 105 \\
\hline Temperatura do ar $\left({ }^{\circ} \mathrm{C}\right)$ & 26 & 24 & 26 & 26 & 26 & 24 \\
\hline Temperatura da água $\left({ }^{\circ} \mathrm{C}\right)$ & 24 & 24 & 25 & 26 & 26 & 18 \\
\hline Nitratos $(\mu \mathrm{g} / 1 \mathrm{~N})$ & 1.950 & 900 & 140 & 1.300 & 2.300 & 3.300 \\
\hline Nitritos $\left(\mu_{g / l} N\right)$ & 40 & 26 & 45 & 13 & 32 & 210 \\
\hline Alcalinidade $\left(\mathrm{mg} / 1 \mathrm{CaCO}_{3}\right)$ & 40 & 38 & 52 & 38 & 40 & - \\
\hline Cloretos $(\mathrm{g} / \mathrm{l} \mathrm{Cl})$ & 7,5 & 9,31 & 4,9 & 0,98 & 7,35 & 9,8 \\
\hline Turbidez (UNT) & 22,5 & 26,5 & 16,0 & 13,0 & 17,5 & 34,5 \\
\hline D.B.O. $(\mathrm{mg} / \mathrm{l})$ & 2 & 9,79 & - & - & - & - \\
\hline Precipitação $\left(\mathrm{mm}^{3}\right)$ & 0,0 & 7,2 & 95,4 & 163,3 & 154,7 & 119,5 \\
\hline
\end{tabular}

\section{DISCUSSÃO}

Dentre os táxons identificados em nível infragenérico, $68,7 \%$ foram registrados como sendo a primeira ocorrência para o Estado de Goiás. Em relação à riqueza específica, a classe mais representativa durante os períodos de 31/08/94, 04/10/ 94, 31/10/94 e 24/02/95 foi Chlorophyceae. Cyanophyceae foi a segunda, nos períodos de 31/08/94, 31/10/94, 31/01/95 e 03/04/95. A classe Euglenophyceae destacou-se principalmente em 31/10/ 94 e 24/02/95. A diversidade específica foi elevada (2,242 a 4,720 bits/ind).

Nos 6 períodos estudados, a densidade variou de $207 \mathrm{ind} / \mathrm{ml}$ (período de seca) a $13.590 \mathrm{ind} / \mathrm{ml}$ (início de chuva). De acordo com Tabela 1, apenas na segunda amostragem foi registrado um táxon dominante. No período de 31/08/94 registrou-se 4 espécies abundantes. $\mathrm{Na}$ amostragem de $04 / 10$ / 94, Koliella longiseta f. tenuis foi a única dominante. Neste mesmo período, as espécies abundantes foram Cosmarium sp. e Cyclotella meneghniana. No período de 31/01/95, somente registrou-se densidades abundantes das seguintes algas: Planktolyngbya subtilis, Cyclotella meneghniana e um táxon não-identificado. Em 24/ 02/95, 10 espécies foram abundantes. Já no período de 03/04/95, predominou abundantemente a alga Cyclotella meneghniana. Além desses táxons, destacam-se: Dictyosphaerium pulchellum, 
Monoraphidium minutum e Lepocinclis ovata como os táxons mais freqüentes.

A afinidade entre os inventários de cada amostragem apresentou baixa similaridade. Notou-se que o período seco mais evidente (31/08/94) foi o que obteve a maior afinidade; este se uniu com o período chuvoso (24/02/95) em $35 \%$ de ocorrências comuns. O período seco (04/10/94) separou-se desses dois anteriores por apresentar apenas $23,8 \%$ de similaridade da ocorrência de espécies comuns, destacando-se pela presença de 18 táxons, cuja reocorrência foi pouco evidente. Os dois períodos de chuva (31/01/95 e 03/04/95) apresentaram 23,5\% de sua ficoflórula comum, distanciando-se em $85 \%$ das características dos demais períodos. Observouse no Lago II que as espécies, na maioria, eram nanoplanctônicas. Os dados indicaram a ocorrência de uma flutuação caracterizada pela mudança na composição florística e na densidade das algas encontradas nesse ambiente a cada período de estudo.

De um modo geral, a diversidade específica foi alta (Tabela 3) e manteve-se acima de 2,242 bits/ind (período seco: 04/10/94), chegando a atingir 4,720 bits/ind (período de chuva: 24/02/95). A densidade fitoplanctônica do Lago II no final da seca e início das chuvas foi diminuindo à medida que aumentou a precipitação.

TABELA 3

Total (ind/ml), riqueza específica (no de táxons), diversidade (H’) e eqüidade (E) dos táxons registrados no ambiente de estudo durante as amostragens.

\begin{tabular}{|c|c|c|c|c|c|c|}
\hline \multirow{2}{*}{ Informações Sobre a Comunidade } & \multicolumn{2}{|c|}{ Seca } & \multirow{2}{*}{$\begin{array}{c}\text { Início de chuva } \\
31 / 10 / 94\end{array}$} & \multicolumn{3}{|c|}{ Chuva } \\
\hline & 31/08/94 & 04/10/94 & & $31 / 01 / 95$ & 24/02/95 & $03 / 04 / 95$ \\
\hline Total (ind/ml) & 207 & 812 & 13.590 & 544 & 276 & 480 \\
\hline Riqueza específica ( $\mathrm{N}^{\circ}$ de táxons) & 27 & 18 & 30 & 14 & 28 & 12 \\
\hline Diversidade específica (bits/ind) & 2,944 & 2,242 & 4,619 & 3,735 & 4,720 & 3,374 \\
\hline Eqüidade & 0,612 & 0,538 & 0,941 & 0,981 & 0,962 & 0,941 \\
\hline
\end{tabular}

No presente estudo, observou-se que a eqüidade foi elevada no início e durante as chuvas e baixa no período seco, enquanto a maior riqueza específica foi registrada no início das chuvas.

No início da estação chuvosa, a alcalinidade apresentou-se elevada, (Tabela 2), registrando-se maior densidade fitoplanctônica (Tabela 3), e houve um decréscimo da turbidez da água. Chlorophyceae foi a classe que congregou a maior densidade, porém não houve espécies dominantes. Nesse mesmo período, 18 táxons foram abundantes; dentre estes destacaram-se: Nephrochlamys allanthoidea e Phacus dangeardi (Tabela 1).

Com a elevação da precipitação, a turbidez aumentou, provavelmente, devido às partículas carreadas da margem. A baixa turbidez observada no Lago II, no período da seca, talvez seja causada pela dimensão das partículas em suspensão, em especial fitoplâncton.

Os níveis de nitratos estiveram mais elevados no período chuvoso, provavelmente devido ao carreamento do solo da margem do lago. Segundo
Esteves (1988), em lagos tropicais, a concentração e a distribuição de nitrato parecem estar diretamente relacionadas ao grau de oxigenação da coluna d'água.

Observou-se que os níves de oxigênio no período chuvoso estiveram acima de $66 \%$ de saturação (Tabela 2). De acordo com os dados obtidos no Lago II, e comparado com os de Vollenweider (1974), o nitrito não assumiu ainda significância, enquanto o nitrato descreveu o Lago II de oligo (04/10/94 e 31/10/94) a mesotrófico (31/08/94, 31/01/95 e 03/04/95). De acordo com a densidade fitoplanctônica, o Lago II esteve eutrofizado em quase todos os períodos, à excessão do período de $31 / 10 / 94$, quando esteve muito eutrófico.

Apesar de a eqüidade e a diversidade indicarem um ambiente equilibrado, o conjunto de informações levantadas demonstrou que a característica mais marcante do lago artificial estudado foi a manutenção de águas, meso e eutróficas, em relação ao nitrato e à densidade fitoplanctônica. 
Agradecimentos - Gostaríamos de agradecer à Dra. Mariângela Menezes pelo auxílio na confirmação das espécies de fitoflagelados e a Msc. Maria das Graças Sophia pela confirmação das desmidiáceas. À FUNAPE/PPRG-UFG pelo auxílio à pesquisa no 069/96. À SANEAGO e FEMAGO pela utilização de suas dependências para o processamento das amostras.

\section{REFERÊNCIAS BIBLIOGRÁFICAS}

AGUIAR, L. W. \& MARTAN, L., 1979, Diatomáceas de lagos do Parque Zoológico, Rio Grande do Sul, Brasil. Iherengia, Sér. Bot., 25: 27-110.

AGUJARO, L. F., 1991, Algas epífitas em Spirrodela oligorrhiza (Lennaceae) de um tanque artificial de São Paulo, SP, Brasil. 1: Tribophiceae (= Xanthophyceae). Hoehnea, 18(2): 31-55.

ALMEIDA, M. A. M. A., 1979, Aspectos ecológicos do Lago Paranoá. Dissertação de Mestrado, Universidade de Brasília, Brasília, 182p.

ALVES-DA-SILVA, S. M. \& TORRES, J. R., 1994, Estudo taxonômico do gênero Phacus. Duj. (Euglenaceae) no Parque Zoológico, Sapucaia do Sul, e no Jardim Botânico, Porto Alegre, Rio Grande do Sul. Iherengia, Sér. Bot., 44: 44-83.

ANAGNOSTIDIS, K. \& KOMÁREK, J., 1988, Modern approach to the classification system of Cyanophytes. 3Oscillatoriales. Arch. Hydrobiol. Suppl., 80(1-4): 327472.

ANDRADE, R. M., 1969, Nota ecológica sobre o Lago da Pampulha (Belo Horizonte, MG) com especial referência aos Planorbídeos (Pulmo-natal, Planorbidae) Rev. Brasil. Malar. Doenç. Trop., 21(1): 59-116.

BICUDO, D. C., 1984, Algas epífitas (exceto diatomáceas) do Lago das Ninféas, São Paulo: levantamento e aspectos ecológicos. Tese de Doutorado, UNESP, Rio Claro, 479p.

BICUDO, D. C., 1996, Algas epífitas do Lago das Ninféas, São Paulo, Brasil, 4: Chlorophyceae, Oedogoniophyceae e Zygnemaphyceae. Rev. Brasil. Biol., 56(2): 345-382.

BICUDO, C. E. M. \& BICUDO, R. M. T., 1970, Algas de águas continentais brasileiras: chave ilustrada para identificação de gêneros. EDUSP/FUNDEC, São Paulo, $228 \mathrm{p}$.

BRANCO, C. W. C. \& SENNA, P. A. C., 1994, Factors influencing the development of Cylindrospermopsis raciborskii and Microcystis aeruginosa in Paranoá Reservoir, Brasília, Brazil. Arch. Hydrobiol., 75: 85-96.

BRANCO, S. M., 1966, Estudos das condições sanitárias da Represa Billings. Ardros. Fac. Hig. Saúde Públ. Univ. São Paulo, 20(1): 57-86.

BRANCO, S. M., 1976, Análises de alguns aspectos e soluções prováveis para o Lago Paranoá. Rev. D. A. E., 36(109): 3845.

BRANCO, C. W. C. \& SENNA, P. A. C., 1991, The taxonomic elucidation of the Paranoá Lake (Brasília, Brazil) problem: Cylindrospermopsis raciborskii. Bull. Jard. Bot.
Belg., 61: 85-91.

BRANCO, C. W. C. \& SENNA, P. A. C., 1996a, Relations among heterotrophic bacteria, chlorophylla, total phytoplankton, total zooplankton and physical and chemical feactures in the Paranoá Reservoir, Brasília, Hidrobiol., 337: 171-181.

BRANCO, C. W. C. \& SENNA, P. A. C., 1996b, Phytoplankton composition, community structure and seasonal changes in a tropical resevoir (Paranoá Reservoir, Brazil). Arch. Hydrobiol., 81: 69-84.

CAMPOS, I. F. P. \& MACEDO-SAIDAH, F. F., 1990, Flórula da represa da escola de agronomia da Universidade Federal de Goiás, Goiânia, Goiás, Brasil. In: Anais do XXXVI Congresso Nacional de Botânica de Curitiba, IBAMA/SBB, Brasília, pp. 839-857.

CAMPOS, I. F. P. , RIZZO, J. A. , CAMARGO, S. \& LOURENÇO, R., no prelo, Estudo qualitativo das Nostocophyceae (Cyanophyceae) da bacia hidrográfica do Ribeirão João Leite, Município de Goiânia, Goiás, Brasil. In: Anais I Congresso Nacional de Ciência y Tecnologia, Cochabamba, Bolívia.

CECY, I. T., 1986, Estudo das algas microscópicas (Nostocophyta, Euglenophyta, Chrysophyta e Chlorophyta) do Lago do Parque Barigüi, em Curitiba, Estado do Paraná, Brasil. Arq. Biol. Tecnol., 29(2): 383.

CECY, I. T., MOREIRA, I. M. V. \& HOHMANN. E., 1976, Estudo ficológico e químico-bacteriológico da água do tanque do Passeio Público de Curitiba, Estado do Paraná, Brasil, 1: gêneros de algas microscópicas. Bol. Mus. Bot. Munic., 25: 1-37.

CHAGAS, L. C. S., 1994, Análise preliminar da comunidade fitoplanctônica do reservatório de água da Chácara São José, Campus II. Monografia de Bacharelado, Universidade Católica de Goiás, Goiânia, 27p.

CHAVES, C. M., 1978, Caracterização ecológica da autodepuração de Lagos do Parque Zoológico de São Paulo. Dissertação de Mestrado, Faculdade de Saúde Pública, USP, pp. 1-61.

CLESCERI, L. S., GREENBERG, A. E. \& TRUSSELL, R. R., 1992, Métodos normalizados para el analisis de águas potables y residuales. $17^{\mathrm{a}}$ ed., Ediciones Diaz de Santos S.A/American Public Health Association, American Water Works Association/Water Pollution Control Federation, Madrid, 10 cap.

CRISPIM, W. M. C., REBOUÇAS-BESSA, M. R. \& OSÓRIO, N. B., 1992, Avaliação do comportamento de um sistema de lagoa de estabilização em série tratando esgotos domésticos, Região Centro-Oeste do Brasil. In: V Simpósio Luso-Brasileiro de Engenharia Sanitária Ambiental, SESA, Lisboa, pp. 163-173.

CRONBERG, G., 1976, Projeto de recuperação do Lago Paranoá: ecologia e taxonomia do fitoplâncton. Relatório preliminar para a CAESB, Brasília (Projeto OPAS/ OMS:76/PW/BRA/2000), 17p.

DERISIO, J. C. \& MONTEBELLO, L., 1972, Relatório do levantamento das condições sanitárias da Represa Bill- 
ings. CETESB, São Paulo, pp. 1-174.

DIAS, I. C. A., 1983, Zygnemaceae (Zygnemaphyceae) do Município do Rio de Janeiro e arredores. Rickia, 10: 85104.

DIAS, I. C. A., 1985, Contribuição ao conhecimento das algas do gênero Mougeotia C. Agardh (Zygnemaphyceae), no Estado do Rio de Janeiro, Brasil. Nova série, no 70, Boletim do Museu Nacional, pp. 1-7.

DIAS, I. C. A., 1992, Algas continentais do Estado do Rio de Janeiro, Brasil: Oedogoniaceae e Zygnemaceae. Hoehnea, 19(1/2): 51-63.

DIAS, I. C. A. \& SOPHIA, M. G., 1994, Desmidiaceae, Oedogoniaceae e Zygnemaceae. In: I. F. P. Campos, J. A. Rizzo \& H. D. Pereira (eds.), Flora dos Estados de Goiás e Tocantins - Criptógamos, 3(1), 56p.

ESTEVES, F. A., 1988, Fundamentos de limnologia. Interciência/FINEP, Rio de Janeiro, 575p.

ETTL, H., 1978, Xanthophyceae. In: H. Ettl, J. Gerloff \& H. Heynig (eds.), Süsswasserflora von Mitteleuropa, Band 3, Gustav Fischer Verlag, Stuttgart, 530p.

FERREIRA, C. J. A., 1988, Análise da distribuição espaçotemporal da comunidade fitoplanctônica da lagoa de estabilização do Guará I. Dissertação de Mestrado, Universidade de Brasília, Brasília, 115p.

FLORES, F. E. V., 1972, Lista de gêneros de Chlorophyta de um lago artificial de Porto Alegre, RS, Brasil. Iheringia, Sér. Bot., 16: 9-13.

FREITAS, J. S., 1983, Variação sazonal e distribuição vertical de microcrustáceos planctônicos no Lago Paranoá. Dissertação de Mestrado, Universidade de Brasília, Brasília, $110 \mathrm{p}$.

GIANI, A., 1984, Distribuição horizontal do fitoplâncton e zooplâncton no Lago Paranoá. Dissertação de Mestrado, Universidade de Brasília, Brasília, 148p.

GIANI, A. \& PINTO-COELHO, R. M., 1986, Contribuição ao conhecimento das algas fitoplanctônicas do reservatório do Paranoá, Brasília, Brasil: Chlorophyta, Euglenophyta, Pirrophyta e Schizophyta. Rev. Brasil Bot., 9(1): 45-62.

HAMMER, M. J., 1979, Sistemas de abastecimento de água e esgotos. Livros técnicos e científicos, Rio de Janeiro.

HOLLANDE, A., 1942, Étude cytologique el biologique de quelques Flagellées libres. Archs Zool. Exp. Gén., 83(1): $1-268$

HINO, R. \& TUNDISI, J. G., 1977, Atlas de algas da Represa do Broa. Universidade Federal de São Carlos, São Carlos, v.2, pp.1-143.

HINDAK, F., 1987, Taxonomic survey of the genera Fusola (Chlorococcales), Elakatothrix, Closteriospira and Chadefaudiothrix (Ulotrichales). Preslia, 59: 193-228.

JOLY, A. B., 1963, Gêneros de algas de água doce da cidade de São Paulo e arredores. Rickia (supplement): 1: 1-188.

KLEEREKOPER, H., 1937, Biologia da Represa Velha de Santo Amaro (Represa Guarapiranga). Rev. D. A. E., 1(2): 151-161.

KLEEREKOPER, H., 1939, Estudo limnológico da Represa de Santo Amaro. Ser. Bot., Bolm. Fac. Filos. Ciênc., Univ.
S. Paulo., 17: 1-151

KOMÁREK, J. \& FOTT, B., 1983, Chlorophyceae (Grünalgen), Ordiniung: Chlorococcales, In: G. HuberPestalozzi, (ed.), Das phytoplankton des süsswasers; systematik und biologie, Band 7(1), E. Schwiezerbat'sche Verlagsbuch - handlung, Stuttgart, $1044 \mathrm{p}$

KREBS, C. J., 1989, Ecological Methodology. University of Britisch Columbia/Harper \& Row, Publishers, New York, pp.328-360.

LANGE-BERTALOT, H., 1979, Pollution tolerance of Diatoms as criterion for water quality estimation. Nova. Hedwigia, 64: 285-303.

LEITE, C., 1974, Contribuição ao conhecimento das Chlorococcales (Chlorophyceae) planctônicas do Parque Estadual das Fontes do Ipiranga, Brasil. Dissertação de Mestrado, USP, São Paulo, 151p.

LINDMARK, G., 1977, The Paranoa Lake restoration project: bioassays field and laboratory experiments and phytoplancton producturty final report to CAESB (Project PAHO/WHO: 77/BRA/2341/04). Brasília, Relatório, 80p.

LOBO, E. \& LEIGHTON, G., 1986, Estructuras comunitarias de las fitocenosis planctonicas de los sistemas de desembocaduras de rios y esteros de la zona central de Chile. Rev. Biol. Mar., 22(1): 1-29.

LUND, J. W. G., KIPLING, C. \& LECREN, E. D., 1958, The inverted microscope method of estimating algal number and the statistical basis of estimating by counting. Hydrobiologia, 11: 143-170.

LYRA, L. T., 1974, Diatomáceas de tanques do cactário do Jardim Botânico Guanabara, Brasil. Mem. Inst. Oswaldo Cruz, 72(1/2): 103-118.

MACEDO-SAIDAH, F. E. M., NASCIMENTO, M. R. R. \& CAMPOS, I. F. P., 1987, O plâncton das águas do Rio Meia Ponte, Município de Goiânia, Goiás, Brasil. Nerítica Suppl., 2: 105-117.

MARTINS, D. V., SANTANA, C. L. \& OLIVEIRA, O. C., 1991, Estudo qualitativo do fitoplâncton do Dique do Tororó, Salvador, Bahia, Brasil. Rev. Brasil. Biol., 51(2): 445-453.

MATSUMURA-TUNDISI, T \& TAVARES, L. H. S., 1986, Phytoplankton. Composition of Broa Reservoir and its utilization by argyro-diaptomus furcatus (Copepoda-Calanoida) In: C. E. Bicudo, C. Teixeira \& J. G. Tundisi (eds.), Algas: a energia do amanhã, Ins. Oceanogr/USP, São Paulo, pp. 183-188.

MENEZES, M., 1987, Polimorfismo em Lepocinclis ovum (Ehrenberg) Lemmermann e suas implicações taxonômicas. Rickia, 14: 1-6.

MENEZES, M., 1989, Contribuição ao conhecimento das algas do gênero Euglena (Euglenophyceae) no Município do Rio de Janeiro e arredores, Brasil. Acta Bot. Bras., 3: 49-89.

MENEZES, M., 1990, Estudos taxonômicos sobre o gênero Lepocinclis Perty (Euglenaceae) no Município do Rio de Janeiro e arredores, Brasil. Rev. Brasil. de Biol., (1): 103113.

MENEZES, M., 1991a, Trachelomonas (Euglenophyceae) do 
município do Rio de Janeiro e arredores, R.J, Brasil. Hoehnea, 18(2): 57-73.

MENEZES, M., 1991b, O gênero Phacus (Euglenaceae) no município do Rio de Janeiro e arredores, Brasil. Hoehnea, 18(1): 171-189.

MENEZES, M., 1992, Considerações sobre a ocorrência de polimorfismo em Lepocinclis salina (Euglenophyceae). Rev. Brasil. Biol., 52(1): 7-13.

MENEZES, M., 1995, Dinoccocales (Dinophyceae) da Região Sul do Município do Rio de Janeiro, Brasil. Hoehnea, 22(1/2): 17-26.

MENEZES, M., 1996, New species of pigmented flagellates from Southeastern Brazil. Arch Protistenkd., 147: 101105.

MENEZES, M., NASCIMENTO, E. P. \& FONSECA, C. G., 1995, Euglenophyceae. In: I. P. F. Campos, J. A. Rizzo \& H. D. Pereira (coords.), Flora dos Estados de Goiás e Tocantins, Criptógamos, $4^{\circ}$ v., CEGRAF, UFG/ABEU, Goiânia, 77p.

NECCHI-JR, O. \& BICUDO, D. C., 1992, Criptógamos do Parque Estadual das Fontes do Ipiranga, São Paulo, SP. Algas, 3: Rhodophyceae. Hoehnea, 19(1/2): 89-92.

NOGUEIRA, I. S., 1996, Botryococcaceae, Radiococcaceae e Oocystaceae (Chlorellales, Chlorophyta) do Município do Rio de Janeiro e arredores, RJ, Brasil. Rev. Brasil. Biol., 56(4): 677-696.

PAIVA, C. S., 1994, Algas planctônicas do Lago das Rosas, Município de Goiânia, Goiás. Monografia de Bacharelado, Universidade Católica de Goiás, Goiânia, 68p.

PAULA, J. E., DORNELLES, L. D. C. \& ALBUQUERQUE, J. D. L., 1982, Vegetação aquática e ciliar da bacia do Lago Paranoá e sua relação com a vida da ictiofauna (área de cerrado). Biol. Tec. IBDF, 7: 39-85.

PEIXOTO, J. A. \& HUSZAR, V. L. M., 1983, Algumas espécies de algas da Quinta da Boa Vista, Rio de Janeiro. Nova sér., Bot. Bolm. Mus. Nac., Rio de J., 67: 1-8.

PICELLI-VICENTIN, M. N., 1987, Chlorococcales planctônicas do Parque Regional do Iguaçu, Curitiba, Estado do Paraná. Rev. Brasil. Biol., 47(1/2): 57-85.

PINTO-COELHO, R. M., 1983, Efeitos do zooplâncton na composição qualitativa e quantitativa do fitoplâncton no Lago Paranoá. Dissertação de Mestrado, Universidade de Brasília, Brasília.

PINTO-COELHO, R. M. \& GIANI, A., 1985, Variações sazonais do fitoplâncton e fatores físico-químicos da água no reservatório do Paranoá, Brasília, DF. Ciênc. e Cult., 37(12): 2000-2006.

REBOUÇAS-BESSA, M. R. \& REIS, C. V., 1992, Variação entre a composição do plâncton da captação da Represa Samambaia e da captação do Rio Meia Ponte na cidade de Goiânia, Brasil. In: Anais XXIII Congresso Interamericano de Ingenieria Sanitaria Ambiental, Tomo I, CUBAIDIS/AIDIS, Havana, pp. 3-19.

REBOUÇAS-BESSA, M. R. \& SANTOS, C. R. A., 1995, Fitoplâncton e fatores fisíco-químicos em lagos do Bosque dos Buritis, no Município de Goiânia, Goiás. In: Anais do
Word-Wide Symposium Pollution in Large Cities, Science and Techonology for planning environmental quality. Abes/Andis/Aidis, Venice/Padora, pp. 17-26.

RENNÓ, L. R., 1958, Aspectos fitolimnéticos da Represa da Pampulha. Bolm. Agric. Dep. Prod. Veg., 7(3/4): 11-49.

ROCHA, A. A. \& NARDUZZO, M., 1975, Aspectos ecológicos dos lagos do Parque Zoológico de São Paulo. Rev. D.A.E., 35(103): 45-51.

ROHLF, F. J., 1992, NT Sys-pc: numerical taxonomy and multivariate analysis system. Version 1.70. Exeter Software, New York, 218p.

ROQUE, R., 1980, Aspectos ecológicos-sanitários e fitoplâncton na Represa Billings. Dissertação de Mestrado, USP, São Paulo, 87p.

ROSA, Z. M., AGUIAR, C. W. \& CORTE-REAL, M., 1974, Notas sobre gêneros de algas continentais do Município de Porto Alegre, RS, Brasil. Sér. Bot., Iheringia, 19: $53-$ 62.

ROUND, F. E., 1983, Biologia das algas. $2^{\text {a }}$ ed., Ed. Guanabara Dois, Rio de Janeiro, 263p.

SANEAGO, 1996, Relatório do monitoramento do Ribeirão João Leite - período 94-95. Saneamento de Goiás S.A, Goiânia, 66p.

SANT’ANNA, C. L., 1984, Chlorococcales (Chlorophyceae) do Estado de São Paulo, Brasil. Bibl. Phycol., 67: 1-348.

SANT'ANNA, C. L., AZEVEDO, M. T. \& SORMUS, L., 1989, Fitoplâncton do Lago das Garças, Parque Estadual das Fontes do Ipiranga, São Paulo, SP, Brasil: estudo taxonômico e aspectos ecológicos. Hoehnea, 16 : 89-131.

SENNA, P. A. C., 1994, Cyanophyceae de la Région Est du District Federal, Brésil, 1. Bull. Jard. Bot. Nat. Belg., 63: 81-100.

SENNA, P. A. C., 1994, Cyanophyceae from the Eastern Region of Distrito Federal, Brazil. Hydrobiologia, 337: 171-181.

SENNA, P. A. C., 1996, Cyanophyceae, from the eastern region of Distrito Federal, Brazil. 2. Bull. Nat. Plantentuin Belg., 65: 73-102.

SIMONSEN, R., 1979, The diatom system: ideas on phylogeny. Bacillaria, 2: 9-70.

SNEATH, P. H. \& SOKAL, R. R., 1973, Numerical taxonomy: the principles and practice of numerical classification. W. H. Freeman and Co., San Francisco, 573p.

SOPHIA, M. G., 1987, Contribuição ao conhecimento das desmideas de hábito filamentoso do Estado do Rio de Janeiro, Brasil. Rickia, 14: 21-35.

STARMACH, K., 1985, Chrysophyceae und Haptophyceae. In: H. Ettl, J. Gerloff \& H. Heynig (eds.), Süsswasserflora von mitteleuropa, Band 1, Gustavo Fisher Verlag, Stuttgart, 515p.

TAVARES, A. S., 1981, Estudo ficológico do lago da Universidade Federal de Santa Catarina, Florianópolis, Brasil Insula, 11: 27-69.

TUNDISI, J. G., 1977, Produção primária, “standing-stock”, 
fracionamento de fitoplâncton e fatores ecológicos em ecossistema lacustre artificial. Tese de Titulação, USP, Represa do Broa, São Carlos, 409p.

TUNDISI, J. G. \& HINO, 1981, List of species and growth seasons of phytoplankton from Lobo (Broa) reservon. Rev. Brasil. Biol., 41(1): 63-68.

UHELINGER, V., 1964, Étude statistique des methodes de dénombrement planctonique. Arch. Sci., 17(2): 121-223.

UTERMÖHL, H., 1958, Zur vervollkommung der quantitativen phytoplancton-methodik. Mitt. Int. Verein. Limnol., 9: 1-38.

VOLLENWEIDER, R. A., 1974, A Manual on methods for measuring primary production in aquatic enviroments. IBP. ํำ 12, 2a ed., Blackwell Sci. Publ., Oxford, 213p.

XAVIER, M. B., 1981a, Represa Billings - São Paulo. I. Fitoplâncton: características físicas da água. Bolm. Inst. Pesca, 8: 23-46.

XAVIER, M. B., 1981b, Represa Billings - São Paulo. II. Variação sazonal do fitoplâncton. Bolm. Inst. Pesca, 8 : 47-64.

XAVIER, M. B., 1989a, O gênero Lepocinclis Perty de lagos do Parque Estadual das Fontes do Ipiranga, São Paulo, Brasil. Hoehenea, 16: 133-147.

XAVIER, M. B., 1989b, O gênero Phacus Dujardim de lagos do Parque Estadual das Fontes do Ipiranga, São Paulo, Brasil. Hoehenea, 16: 149-164. 